San Jose State University

SJSU ScholarWorks

Master's Theses

Master's Theses and Graduate Research

1990

\title{
HEME requirement and effect of medium surface area exposure on population growth and ATP production of Caenorhabditis elegans
}

Claudine Chang

San Jose State University

Follow this and additional works at: https://scholarworks.sjsu.edu/etd_theses

\section{Recommended Citation}

Chang, Claudine, "HEME requirement and effect of medium surface area exposure on population growth and ATP production of Caenorhabditis elegans" (1990). Master's Theses. 39.

DOI: https://doi.org/10.31979/etd.8pd9-g4p6

https://scholarworks.sjsu.edu/etd_theses/39

This Thesis is brought to you for free and open access by the Master's Theses and Graduate Research at SJSU ScholarWorks. It has been accepted for inclusion in Master's Theses by an authorized administrator of SJSU ScholarWorks. For more information, please contact scholarworks@sjsu.edu. 


\section{INFORMATION TO USERS}

The most advanced technology has been used to photograph and reproduce this manuscript from the microfilm master. UMI films the text directly from the original or copy submitted. Thus, some thesis and dissertation copies are in typewriter face, while others may be from any type of computer printer.

The quality of this reproduction is dependent upon the quality of the copy submitted. Broken or indistinct print, colored or poor quality illustrations and photographs, print bleedthrough, substandard margins, and improper alignment can adversely affect reproduction.

In the unlikely event that the author did not send UMI a complete manuscript and there are missing pages, these will be noted. Also, if unauthorized copyright material had to be removed, a note will indicate the deletion.

Oversize materials (e.g., maps, drawings, charts) are reproduced by sectioning the original, beginning at the upper left-hand corner and continuing from left to right in equal sections with small overlaps. Each original is also photographed in one exposure and is included in reduced form at the back of the book.

Photographs included in the original manuscript have been reproduced xerographically in this copy. Higher quality $6^{\prime \prime} \times 9^{\prime \prime}$ black and white photographic prints are available for any photographs or illustrations appearing in this copy for an additional charge. Contact UMI directly to order.

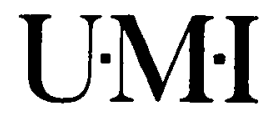

University Microfilms International

A Bell \& Howell Information Company

300 North Zeeb Road. Ann Arbor. MI 48106-1346 USA

$313 / 761-4700 \quad 800 / 521-0600$ 

Order Number 1942701

Heme requirement and effect of medium surface area exposure on population growth and ATP production of Caenorhabditis elegans

Chang, Claudine M., M.S.

San Jose State University, 1990 



\title{
HEME REQUIREMENT AND EFFECT OF MEDIUM SURFACE AREA EXPOSURE ON POPULATION GROWTH AND ATP PRODUCTION OF CAENORHABDITIS ELEGANS
}

\author{
A Thesis \\ Presented to \\ The Faculty of the Department of Nutrition and \\ Food Science \\ San Jose State University
}

In Partial Fulfillment

of the Requirements for the Degree

Master of Science

in Nutritional science

by

Claudine Chang

December, 1990 
APPROVED FOR THE DEPARTMENT OF NUTRITION AND FOOD SCIENCE

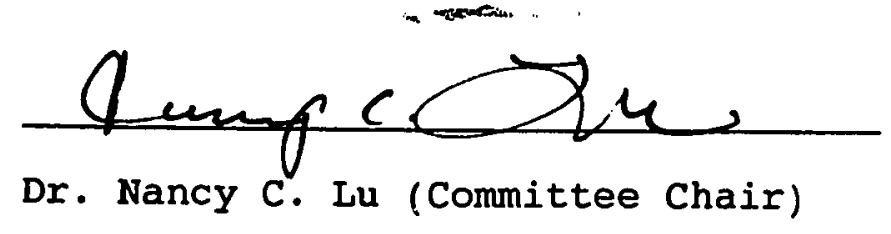

Elude flute

Dr. Elveda Smith

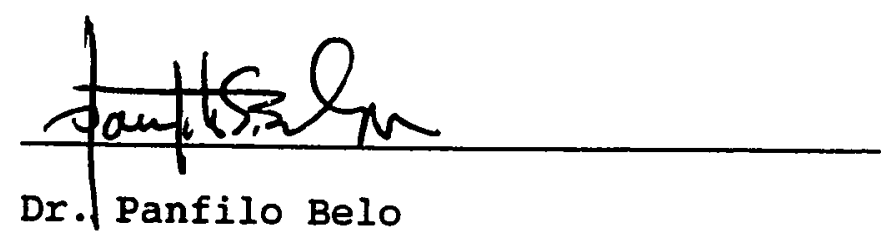

APPROVED FOR THE UNIVERSITY

Serena It. bonfire 


\section{ABSTRACT}

HEME REQUIREMENT AND EFFECT OF MEDIUM SURFACE AREA EXPOSURE ON POPULATION GROWTH AND ATP PRODUCTION OF CAENORHABDITIS ELEGANS

by Claudine chang

The effects of six cytochrome c concentrations $(0,13$, $25,50,100$, and $200 \mu \mathrm{g} / \mathrm{ml}$ ) and three surface area exposures $\left(4.3 \mathrm{~cm}^{2}, 8.2 \mathrm{~cm}^{2}\right.$ and $12 \mathrm{~cm}^{2}$ ) of the culture medium (5 $\left.\mathrm{ml}\right)$ on the population growth and ATP production of $\underline{\text { c. elegans }}$ were studied. Population growth increased rapidly as both cytochrome c concentration and surface area exposure increased. The highest population growth $(93,000$ nematodes/ml) occurred at $200 \mu \mathrm{g} / \mathrm{ml}$ cytochrome $\mathrm{c}$ with the large surface area $\left(12 \mathrm{~cm}^{2}\right)$ exposure. ATP content of c. elegans was determined by bioluminescence. No linear relationship was found between cytochrome c concentrations in the culture medium and ATP content of $c$. elegans. However, ATP content of $\underline{c}$. elegans increased consistently at higher surface area exposure especially during the log phase (days 7 and 14). Under the experimental conditions studied, the effect of surface area exposure of the culture medium is more prominent than the concentration of cytochrome $c$ on ATP production by $\underline{\text {. elegans. }}$ 


\section{ACKNOWLEDGEMENTS}

The author gratefully acknowledges: Dr. Nancy Lu, The Committee Advisor, for her time, patience, and advice throughout all phases of this research; Dr. Elveda Smith for her inspiration, support, and editing; Dr. Panfilo Belo for his valuable suggestions and assistance with manuscript organization; Dr. Robert Phillips of Turner Designs for loaning the luminometer and providing the chemical reagents. The author is also grateful to her husband, Lincoln, for his patience, encouragement, and understanding during the achievement of this personal goal, and her sister, Reel, for her time in word processing. 


\section{PREFACE}

The following is a publication style thesis. The second chapter is written in journal format according to January, 1989 guidelines and will be submitted to the Nematologica. Chapters 1 and 3 are written according to guidelines outlined in the publication Manual of the American Psychological Association (3rd. edition), 1986. 


\section{Table of Contents}

PAGE

List of Figures . . . . . . . . . . . . . viii List of Table.................. ix CHAPTER

1 INTRODUCTION AND REVIEW OF LITERATURE ...... 1 Introduction ............... . . 1

Review of Literature ............. 2

Nematode . . . . . . . . . . . 2

Biological Characteristics of $\underline{c}$. elegans . . . 2

Nutritional Requirements of $\subseteq$. elegans . . . 3

Surface Area Exposures of the Culture Medium . . 10

Bioluminescence ............ 14

2 JOURNAL ARTICLE . . . . . . . . . . 17 Abstract ................. . 19

Introduction . . . . . . . . . . . 19

Materials and Methods ............ 21

Stock Medium ................ 21

Experimental Media ............ 21

Cultivation conditions ........... 21

Extraction and Measurement of ATP ...... 22

Results ............... . 24

Quantitative requirement of cytochrome $c$ and

Surface Area Exposures on Population Growth . 24 vi 
Effects of Surface Area Exposures on ATP Content of Nematode ............. 25 Discussion ................ 26 References ............. 36

3 SUMMARY AND RECOMMENDATIONS . . . . . . . 39 Summary ............... . 39 Recommendations ........... 40

REFERENCES ................. 41 


\section{List of Figures}

FIGURE

PAGE

A The Anatomy of the c. elegans . . . . . . . . . 4

B Postulated Branched Electron Transport system in

the Muscle Mitochondria of A. Lumbricoides . . 11

1 Population Growth of c. elegans at Various

Concentrations of Cytochrome $c$ and Large surface

Areas . . . . . . . . . . . . . . 31

2 Population Growth of $\underline{c}$. elegans at Various

Concentrations of Cytochrome $c$ and Medium Surface

Areas . . . . . . . . . . . . . . 32

3 Population Growth of $c$. elegans at Various

Concentrations of Cytochrome c and small surface

Area . . . . . . . . . . . . . . 33

4 Comparison of Population Growth at Various

Concentrations of Cytochrome $c$ and Surface Areas

in c.. elegans (21 days) . . . . . . . . . . 34 


\section{List of Tables}

TABLE

PAGE

I ATP Production at Various Concentrations of Cytochrome c and surface Area in c. elegans . . - 35 
CHAPTER 1

INTRODUCTION AND REVIEW OF IITERATURE

Introduction

Caenorhabditis elegans (c. elegans) is an egg-laying self-fertilizing free-living nematode. They are easily cultivated to a large population (e.g., 80,000 nematodes/ml) under germ-free conditions in the chemically defined medium established by $\mathrm{Lu}$ and coworkers (1978). Because of the ease of cultivation and short life span (16-20 days in a germfree condition) (Decuyper \& Vanfletern, 1982), C. elegans has been used as model in the studies of aging (Gershon, 1970), genetics (Sulston \& Brenner, 1974), toxicity (Popham \& Webster, 1979), and nutrition (Lu et al., 1983).

Hieb et al. (1970) demonstrated that $c$. briggsae (a closely related species of $c$. elegans) has a nutritional requirement for heme. Reproduction of this organism occurs only when the growth medium is supplemented with a hemeprotein-containing fraction from liver. This liver fraction can be effectively substituted with pure myoglobin, hemoglobin, cytochrome $c$, or hemin. However, cytochrome c is found to be the most effective heme source in supporting reproduction of $\underline{c}$. briggsae.

Free-living nematode such as $\underline{c}$. briggsae require an adequate supply of oxygen for motility, growth, and reproduction. It was demonstrated that ambient air 
consisting $32 \%$ of oxygen speeded up the rate of growth and reproduction in $c$. briggsae cultivated in a glass culture chamber (Nicholas \& Jantunen, 1964, 1966). c. elegans has been axenically cultivated in culture tube (18 $\times 150 \mathrm{~mm})$ on a tissue rotator with a $15^{\circ}$ angle (Lu et al., 1978; Lu et al., 1983; Sun et al., 1986). Oxygen is required in the aerobic metabolism for the production of adenosine triphosphate (ATP) from higher animals to aerobic bacteria (Martin et al., 1983). This function has been identified in some nematodes such as in the muscle mitochondria of Ascaris lumbricoides (Cheah, 1976) and Turbatrix aceti (Atkinson, 1980)

The purpose of this study was to study the quantitative nutritional requirement of cytochrome $c$ by $c$. elegans in a completely chemically defined medium at various surface area exposures. The effect of surface area exposures of the culture medium on ATP production by $\underline{c}$. elegans were also investigated.

\section{Review of Literature}

\section{Nematode}

Biological characteristics of c. elegans. c. elegans is a free-living nematode which has a short generation time of 3-5 days (Nicholas, 1984). The fertilized egg develops into the mature adult in 3.5 days. There are six stages in the life cycle of $c$. elegans: egg, four larval stages, and adult. The larvae develop by moulting, a process of 
shedding the outer cuticle.

c. elegans has a cylindrical body which tapers at the anterior and posterior ends (Figure A). C. elegans has a simple anatomy which is 30 to $80 \mu \mathrm{m}$ in width and 200 to $1100 \mu \mathrm{m}$ in length (Bird, 1980; Nicholas, 1984). The outer covering is a semi-transparent cuticle (composed primarily of collagen) consisting of several layers: epicuticle, cortical, median, and basal layers, which differ structurally and histochemically.

The growth and reproduction of $\underline{c}$. elegans is affected by temperature variation. According to Brun (1965), c. elegans cannot reproduce at temperatures higher than $22^{\circ} \mathrm{C}$. When an embryo is transferred from $18^{\circ}$ to $24.5^{\circ} \mathrm{C}$, it develops into a sterile adult with a normal morphology. When the growth conditions are changed from $18^{\circ}$ to $23^{\circ} \mathrm{C}$, the adult worm has a very low fecundity. When the nematodes were transferred from $18^{\circ}$ to $22^{\circ} \mathrm{C}$, fecundity gradually increased.

Nutritional requirements of c. elegans. c. elegans is cultivated in a completely chemically defined medium (Lu et al., 1978) which is composed of c. briggsae Maintenance Medium (CbMM) and other defined compounds such as sterols ( $\beta$-sitosterol), a heme source (cytochrome c), and a lipid related growth factor (potassium acetate). The $c$. briggsae Maintenance Medium contains predetermined amounts of amino acids, vitamins and growth factors, nucleic acids, glucose, 


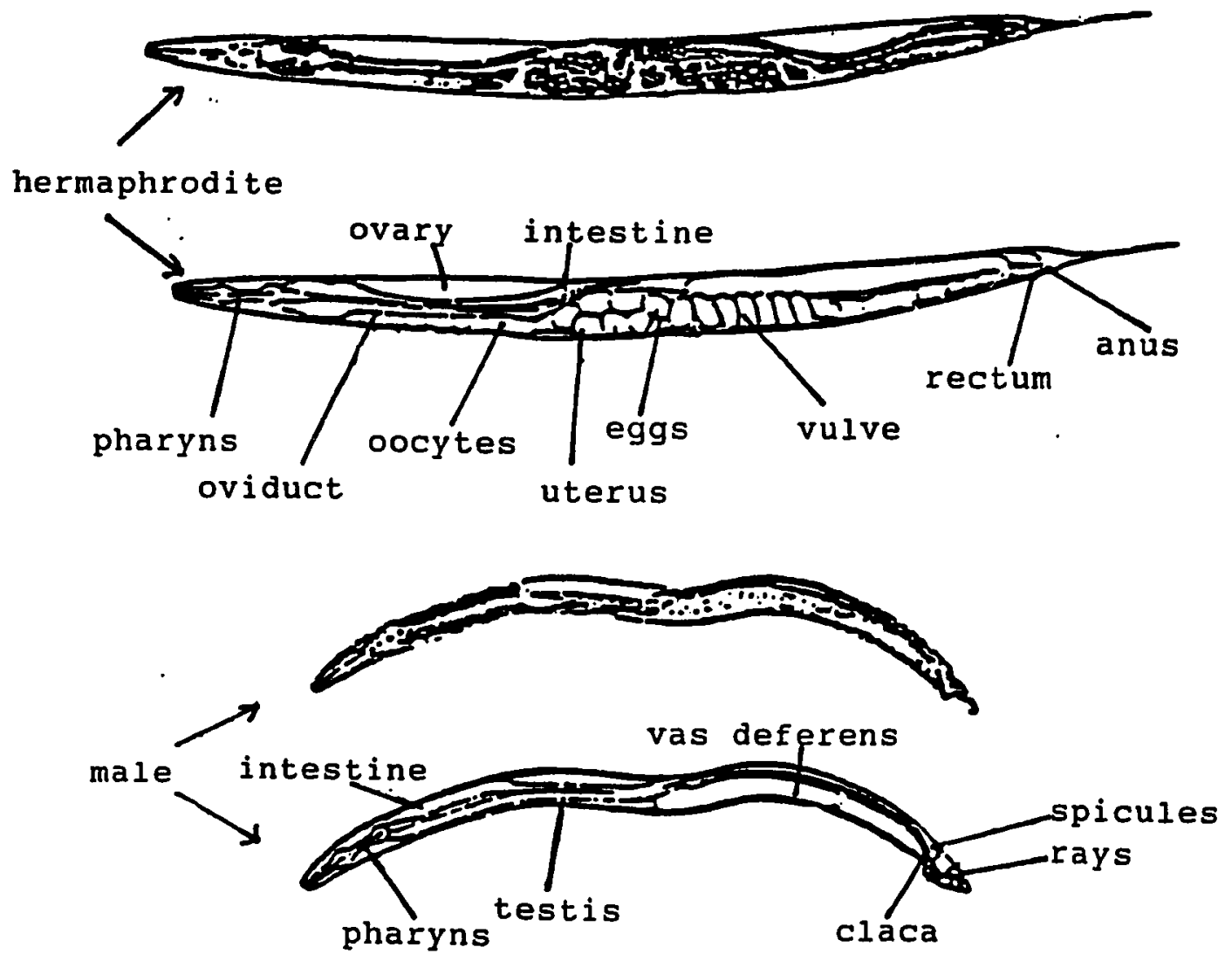

Figure $\underline{A}$. The anatomy of the $\mathbf{c}$. elegans.

Note. From "Caenorhabditis elegans: Getting to Know You" by J.L. Marx, 1984, Science, 225, p. 40 . 
and minerals (Buecher et al., 1966).

Vanfleteren (1973) found that by single omission of amino acids from CbMM, c. briggsae required arginine, histidine, isoleucine, leucine, lysine, methionine, phenylalanine, threonine, tryptophan, and valine, whereas alanine, asparagine, cysteine, glutamine, glycine, proline, serine, and tyrosine are non-essential. However, the minimal requirements of these amino acids for $c$. briggsae are difficult to determine since a change in the level of one amino acid induces a change in the requirement for others.

By systematic omission of B vitamins from CbMM (supplemented with $10 \%$ chick embryo extract), Nicholas et al. (1962) demonstrated the requirement of thiamin, riboflavin, folic acid (pteroylglutamic acid), niacinamide, pantothenic acid, and pyridoxine by $\underline{c}$. briggsae. The folic acid requirement has been studied especially in relation to the metabolism of histidine (Lu et al., 1974). During folic acid deficiency, formimino-L-glutamic acid (FIGLU) accumulates in the tissue of $\underline{c}$. briggsae, and the breakdown of histidine is impaired. The authors suggested that accumulation of FIGLU in $\underline{c}$. briggsae may have inhibited the activities of some folate dependent enzymes (serine hydroxymethyltransferase, methylenetetrahydrofolate dehydrogenase, and formyltetrahydrofolate synthetase) and some glycolytic enzymes (hexokinase, pyruvate kinase, and 
fructose diphosphate aldolase), which eventually interfered with reproduction in c. briggsae. Later in 1976, Lu et al. found that both vitamin $B_{12}$ (cyanocobalamin) and folic acid are required for the conversion of homocysteine to methionine in $\varepsilon$. briggsae. When methionine was omitted from the CbMM in the presence of supraoptimal vitamin $B_{12}$ and folic acid, the population was reduced by $80 \%$. However, when methionine was replaced by $D, L$-homocysteine, the medium was equally effective in supporting the population growth as that containing methionine since both vitamin $B_{12}$ and folic acid are involved in the methylation of homocysteine for the synthesis of methionine.

The effects of vitamin $B_{6}$ (pyridoxal phosphate, pyridoxine, and pyridoxamine) on the growth-promoting activity of $\underline{c}$. elegans were quantitatively determined (Sun et al., 1986). Pyridoxal phosphate generated the greatest growth-promoting activity and exhibited the highest toxicity according to population growth. Both vitamin $B_{6}$ deficiency and toxicity affected the tryptophan metabolism in c. elegans. The accumulation of tryptophan metabolites (xanthurenic and kynurenic acids) in the medium were slightly increased with vitamin $\mathrm{B}_{6}$ deficiency and significantly increased with vitamin $\mathrm{B}_{6}$ toxicity. A biotin requirement was demonstrated by adding avidin, a protein that inhibits the uptake of biotin, but this inhibiting effect is reversed with excess biotin (Nicholas \& Jantunen, 
1963). Ahluwalia and $\mathrm{Lu}$ in 1985 first reported the deficiencies of some other growth factors by deleting each growth factor from CbMM and found that $c$. elegans required N-acetylglucosamine, pantetheine, para-aminobenzoic acid, thioctic acid, choline.dihydrogen citrate, and myo-inositol.

Pertel (1967) found that the omission of uridine, adenine, or the pyrimidines as a group retards the reproduction of c. priggsae. Lu (1973) further studied the effect of nucleotides (adenylate, cytidylate, guanylate, and uridylate) and thymine on folic acid requirement. It was found that omission of all four nucleotides and thymine from CbMM (supplemented with autoclaved E. coli cell residue) containing supraoptimal folic acid reduced the population growth of c. briggsae by 15-20\%. However, the population was further reduced by $65 \%$ at a lower folic acid level, indicating that folic acid requirement is increased in the absence of nucleotides and thymine.

Information regarding carbohydrate requirements by nematodes is limited. The utilization of several carbohydrates (glucose, fructose, sucrose, trehalose, and glycogen) by $c$. elegans was tested in the medium without potassium acetate (Lu \& Goetsch, 1987). Glucose was found to be the most effective carbohydrate for supporting population growth.

The mineral requirement of $\underline{c}$. elegans was studied by the systematic omission of individual mineral salts from 
CbMM and replacement of chloride salts to the medium (Lu et al., 1983). Mineral mixtures containing potassium, magnesium, manganese, sodium, calcium, and copper are required by $c$. elegans. Although the procedures failed to produce a zinc deficiency, there was no evidence that zinc is not required. Iron deficiency was also difficult to develop since $c$. elegans requires an organic iron source (a heme moiety) for population growth, which is satisfied by cytochrome c.

A sterol requirement by $\underline{C}$. briggsae was shown by Hieb and Rothstein (1968). A single sterol or a mixture of sterol compounds such as cholesterol, cholestane, 7-dehydrocholesterol, ergosterol, $\beta$-sitosterol, and stigmasterol can satisfy this requirement. Lu et al. (1977) showed that the optimal amount of sterol ( $\beta$-sitosterol) required by $C$. elegans is $50 \mu \mathrm{g} / \mathrm{ml}$. Lu et al. in 1978 demonstrated that lipid-related compound such as sodium oleate, sodium stearate, Tween 80, Tween 85, ethanol, n-propanol, or potassium acetate was also required for the population growth of $c$ : briggsae.

Heme (iron-containing porphyrin compounds) requirements by the unicellular kingdom (e.g., bacteria, fungi, protozoa) are well documented, but heme is not required by multicellular animals other than nematodes (Hieb, 1977). The heme requirement of $c$. briggsae was first reported by Hieb et al. in 1970. Reproduction of this organism occurs 
only when the growth medium containing sterol, and autoclaved E. coli was further supplemented with a hemeprotein-containing fraction from liver. This liver fraction can be substituted effectively with pure myoglobin, hemoglobin, cytochrome $c$, or hemin. Among these heme compounds, cytochrome $c$ is the most effective heme source in supporting reproduction of $\underline{c}$. briggsae. However, the nutritional requirement of cytochrome $c$ as an essential nutrient has not been quantitatively studied in a completely chemically defined medium.

cytochrome $c$ is part of the cytochrome chain that acts as electron carriers in the oxidative phosphorylation for ATP production. The iron ion in the porphyrin ring structure of cytochrome $c$ undergoes valency changes during oxidation and reduction. Some emphasis has been placed on establishing the presence of cytochrome $c$ as an indicator of oxidative phosphorylation for ATP production in nematodes. Cytochrome $c$ in the electron transport chain was identified in c. briggsae (Deubert \& zuckerman, 1968), T. aceti (Rothstein, 1970), and A. lumbricoides (Cheah, 1976). Cheah (1976) postulated a scheme for the cytochrome chain in the muscle mitochondria of $\mathbf{A}$. lumbricoides (Figure B). The author suggested that the electron transport system in the oxidation of succinate consisted of a major and a minor pathway of electron flow. The major pathway, which contributes about $70 \%$ of succinate oxidation, involves 
transformation of cytochrome b complex to cytochrome 0 , with oxygen being reduced to hydrogen peroxide. Cytochrome $c$ is involved in the minor pathway (about $30 \%$ of succinate oxidation) in which electrons flow via a route from rhodoquinone to cytochrome $a_{3}$, with oxygen being reduced to water. This scheme has been used to explain the important role of cytochrome $c$ in the electron transport chain for the formation of ATP. Free energy is released when electrons move via the cytochrome chain and is captured by adenosine diphosphate (ADP) in the form of high-energy phosphate (ATP). The two possible sites of phosphorylation in the minor pathway, designated as I and II, yield 2 moles of ATP. Surface Area Exposures of the culture Medium

c. elegans are aerobic organisms and require an adequate supply of oxygen for motility, growth, and reproduction. The cultivation of $c$. elegans in liquid medium requires continuous aeration. When oxygen supply is limited by small medium surface exposure, anoxia occurs which is lethal. The effect of anaerobic conditions on the eggs, larvae, and adults of $\underline{c}$. briggsae was investigated by Nicholas and Jantunen (1964). Anaerobic conditions were maintained by exposing the nematodes, in drops of media, to a stream of purified moist nitrogen $\left(\mathrm{N}_{2}\right)$ or hydrogen $\left(\mathrm{H}_{2}\right)$ gas. The nematodes were maintained under germ-free conditions to eliminate any secondary effect caused by bacteria or other organisms. It was observed that swimming 


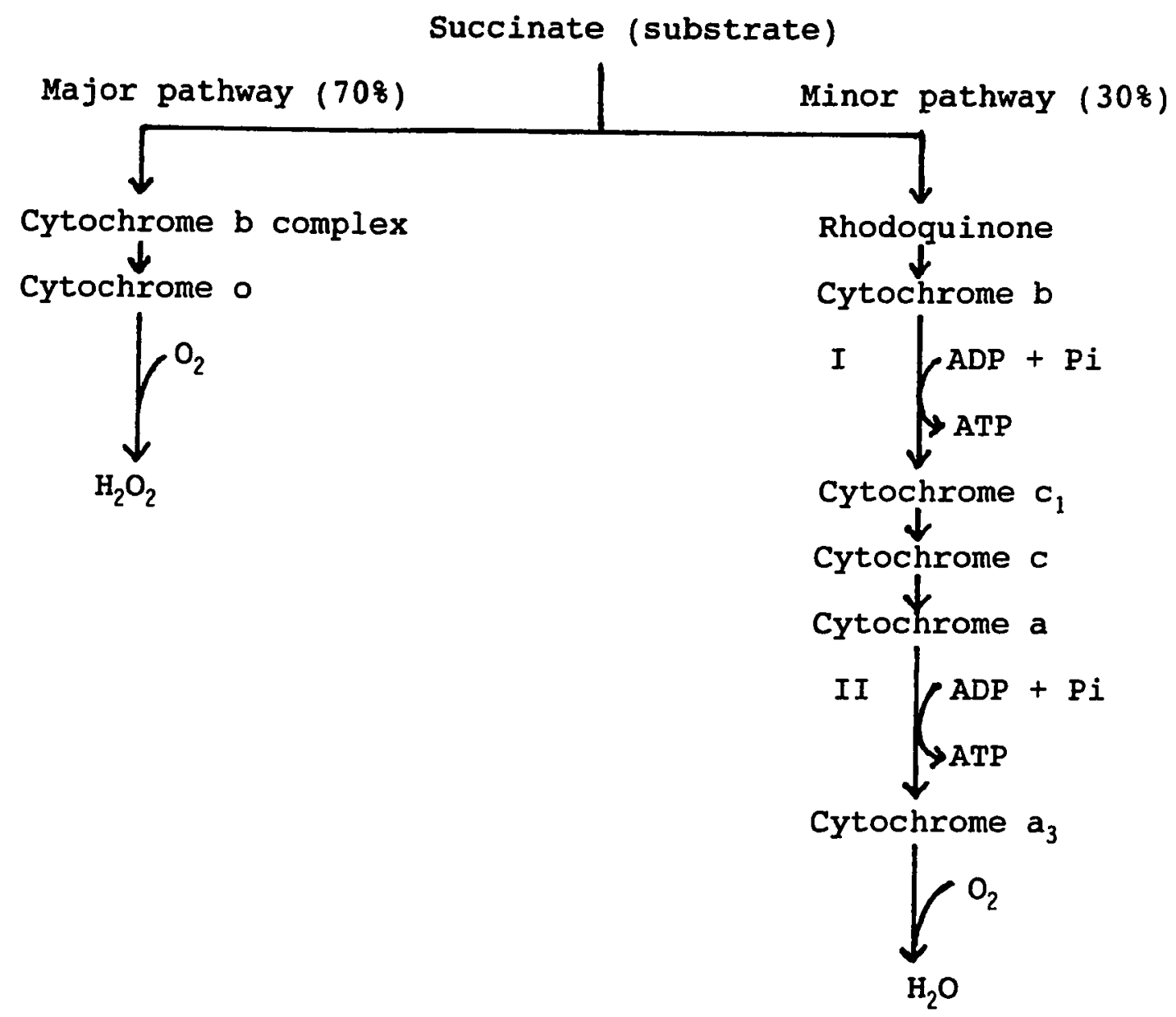

Figure B. Postulated branched electron transport system in the muscle mitochondria of $\underline{A}$. lumbricoides.

Note. From Biochemistry of Parasites (p. 223) by K.S. Cheah, 1976, New York: Academic Press. 
was impaired by oxygen lack, rapidly leading to complete paralysis. Nematodes recovered when returned to aerobic conditions after a short period (4-5 hr) of exposure to $\mathrm{N}_{2}$ or $\mathrm{H}_{2}$ gas, but failed to recover after longer periods of exposure $(24 \mathrm{hr})$. The eggs were more tolerant to the anaerobic conditions than were either the adults or larvae and remained viable for several days. However, hatching was inhibited unless conditions became aerobic.

Nicholas and Jantunen (1966) also studied the effect of different partial pressures of oxygen $\left(\mathrm{PO}_{2}\right)$ on the growth and reproduction of $\mathrm{c}$. briggsae under germ-free conditions. Small amounts of culture medium containing young larva were held in a glass culture chamber and equilibrated with mixtures of oxygen $\left(\mathrm{O}_{2}\right)$, nitrogen $\left(\mathrm{N}_{2}\right)$, and carbon dioxide $\left(\mathrm{CO}_{2}\right)$ gases. The normal $\mathrm{PO}_{2}$ in this experiment was $149 \mathrm{~mm}$ Hg. The development of the culture was observed under the microscope. Growth and reproduction were progressively retarded as $\mathrm{PO}_{2}$ was reduced below $30 \mathrm{~mm} \mathrm{Hg}$ and completely stopped at lower levels (below $1.2 \mathrm{~mm} \mathrm{Hg}$ ). In another study by Anderson and Dusenbery (1977), c. elegans maintained consistent growth and reproduction above a $\mathrm{PO}_{2}$ of $27 \mathrm{~mm} \mathrm{Hg}$. However, below $27 \mathrm{~mm} \mathrm{Hg}$, growth and reproduction were retarded. The cultures also produced more worms per unit volume when the culture medium was in a thin layer in contact with a larger air space than in the deeply filled culture tube. Hansen et al. (1964) made similar 
observations regarding the need for a high level of oxygen by $\underline{c}$. briggsae growing in culture tubes, especially when bacterial contamination occurred. c. briggsae did not grow well in culture tubes when competing with bacteria for oxygen and quickly died since oxygen was rapidly depleted by bacteria. However, contaminated cultures grew well on agar plates with a large air surface and greater oxygen supply. Whereas most higher animals possess complex respiratory and circulatory organs to carry oxygen to the body tissues, nematodes lack both specialized respiratory and complex circulatory organs. Therefore, the cylindrical shape offers a better surface-to-volume ratio for a better oxygen supply through the cuticle.

The level of oxygen also has a significant effect on the energy metabolism of the nematodes. The amount of cellular energy (ATP) produced depends on the metabolic pathway used by nematode. In turn, the type of metabolic pathway used in the nematode depends on the availability of oxygen (Bolla, 1980). The amount of ATP produced by aerobic metabolism is higher than by anaerobiosis (Atkinson, 1980). For instance, aerobic metabolism yields 38 ATP moles per glucose mole catabolized in nematodes, whereas the most efficient anaerobic pathway presently suggested for nematodes provides 5 ATP moles per mole of glucose (Barrett, 1976). Part of the energy released is responsible for locomotion in nemațodes. Under normal conditions, free- 
living nematodes use aerobic metabolic pathway such as tricarboxyic acid cycle (TCA cycle) coupled to cytochromemediated electron transport for ATP production (Bolla, 1980).

\section{Bioluminescence}

Bioluminescence, also known as the firefly luciferinluciferase system, is a process of light-producing reactions which require the presence of the enzyme (luciferase [E]), substrate (luciferin $\left[\mathrm{LH}_{2}\right]$ and ATP), magnesium ion, and oxygen (Whitehead et al., 1979). The light produced is reported to be proportional to the amount of ATP present in the living organisms. The initial reaction is the rapid conversion of luciferin $\left(\mathrm{LH}_{2}\right)$ and ATP to a luciferase: luciferyl adenylate ( $E: \mathrm{LH}_{2}: \mathrm{AMP}$ ) complex in the presence of magnesium ions. This reaction is shown in the following equation:

$$
\mathrm{E}+\mathrm{LH}_{2}+\mathrm{ATP}-\mathrm{Mg}_{--->}^{2+} \mathrm{E}: \mathrm{LH}_{2}: \mathrm{AMP}+\text { pyrophosphate }
$$

This complex reacts with oxygen to produce oxyluciferin (the emitter of light), adenosine monophosphate (AMP), $\mathrm{CO}_{2}$, and light. Carbon dioxide is derived from the carboxyl group of the luciferin. This reaction is shown in the following equation:

$$
E: \mathrm{LH}_{2}: \mathrm{AMP}+\mathrm{O}_{2}--->\mathrm{E}+\text { oxyluciferin }+\mathrm{AMP}+\mathrm{CO}_{2}+\text { light }
$$

The reaction is optimal at $25^{\circ} \mathrm{C}$ in hepes (N-2-hydroxyethylpiperazine-N'-2-ethane-sulphoric acid) buffer at pH 7.75. Moyer and Henderson (1983) investigated the 
specificity of the firefly luciferase with 12 nucleoside triphosphate substrates and found that the luciferase reaction was specific for ATP only. They reported that the interference of other triphosphate substrates was negligible.

Bioluminescence is a rapid and sensitive method for the quantitation of viable cells such as red blood cells and bacteria (Whitehead et al., 1979). Chapelle and Levin (1964) first reported the use of the firefly luminescence assay in the detection of microorganisms. Conn and coworkers (1975) measured ATP in bacteria and found that ATP content varied among species, i.e., Pseudomonas $\left(5 \times 10^{-17} \mathrm{~g}\right.$ ATP/cell), S. epidermidis (8.2 $10^{-16} \mathrm{~g}$ ATP/cell), and marine bacteria (5 $\times 10^{-15} \mathrm{~g}$ ATP/cell). However, based on dry weight, living cells contain approximately $2 \times 10^{-6} \mathrm{~g}$ ATP/mg. Adenosine triphosphate was measured in a nematode culture (about 400 cells per organism) in a preliminary study by Turner Designs (1985), who reported approximately $2 \times 10^{-6} \mathrm{~g} A T P / \mathrm{mg}$ based on the dry weight of nematode tissue.

The extraction of ATP from $\underline{c}$. elegans is a quick process in which dimethyl sulfoxide (DMSO) is used as the extracting reagent. Dimethyl sulfoxide penetrates rapidly to increase cell membrane permeability which allows the rapid release of small molecules such as ATP from mitochondria; larger molecules such as alkaline phosphatases 
(which break down ATP) remain trapped within cell (Karl, 1980) - In addition, Knust et al. (1975) and Lundin et al. (1976) demonstrated that DMSO is five times more efficient than traditional extractants, such as trichloroacetic acid or acetone, in extracting ATP from the multicellular organisms. 
Chapter 2

JOURNAL ARTICLE 


\title{
Authors Title Page \\ HEME REQUIREMENT AND EFFECT OF MEDIUM SURFACE AREA EXPOSURE ON POPULATION GROWTH AND ATP PRODUCTION OF CAENORHABDITIS ELEGANS ${ }^{\prime}$
}

\author{
C. CHANG $^{2}$, N. C. LU, E. SMITH, and P. S. BELO \\ Department of Nutrition and Food Science \\ San Jose State University \\ One Washington Square \\ San Jose, CA 95192
}

1) Presented in part at the 72nd Annual Meeting of the Federation of American Societies for Experimental Biology [Fed. Proc. 2, A1629 (1988)]; supported in part by the San Jose State University Foundation Research Grant.

2) Address questions and comments to: claudine chang

147 West Edith Avenue, Los Altos, CA 94022, (415) 948-3599 


\section{ABSTRACT}

The effects of six cytochrome c concentrations $(0,13$, 25, 50, 100, and $200 \mu \dot{g} / \mathrm{ml}$ ) and three surface area exposures $\left(4.3 \mathrm{~cm}^{2}, 8.2 \mathrm{~cm}^{2}\right.$ and $12 \mathrm{~cm}^{2}$ ) of the culture medium (5 $\left.\mathrm{ml}\right)$ on the population growth and ATP production of $\underline{c}$. elegans were studied. Population growth increased rapidly as both cytochrome c concentration and surface area exposure increased. The highest population growth $(93,000$ nematodes $/ \mathrm{ml}$ ) occurred at $200 \mu \mathrm{g} / \mathrm{ml}$ cytochrome $\mathrm{c}$ with the large surface area $\left(12 \mathrm{~cm}^{2}\right)$ exposure. ATP content of C. elegans was determined by bioluminescence. No Iinear relationship was found between cytochrome c concentrations in the culture medium and ATP content of $c$. elegans. However, ATP content of $c$. elegans increased consistently at higher surface area exposure especially during the log phase (days 7 and 14). Under the experimental conditions studied, the effect of surface area exposure of the culture medium is more prominent than the concentration of cytochrome $c$ on ATP production by $c$. elegans.

Keywords: Germ-free nematode, cytochrome c, culture medium, bioluminescence.

Hieb et al. (1970) demonstrated that c. briggsae has a nutritional requirement for heme. Reproduction of this organism occurred only. when the growth medium containing autoclaved E. coli cells was supplemented with a 
hemeprotein-containing fraction from liver. This liver fraction was effectively substituted by pure myoglobin, hemoglobin, cytochrome c, or hemin. However, cytochrome c was found to be the most effective heme source in supporting reproduction of $c$. briggsae.

Free-living nematodes require an adequate supply of oxygen for motility, growth, and reproduction. It was demonstrated that ambient air consisting $32 \%$ oxygen speeded up the rate of growth and reproduction in $\underline{c}$. briggsae cultivated in a glass culture chamber (Nicholas \& Jantunen, 1964, 1966). c. elegans has been axenically cultivated in culture tube $(18 \times 150 \mathrm{~mm})$ on a tissue rotator with a $15^{\circ}$ angle (Lu et al., 1978; Lu et al., 1983; Sun et al., 1986). oxygen is required in the electron transport chain for the production of adenosine triphosphate (ATP) from higher animals to aerobic bacteria (Martin et al., 1983). This function has also been identified in nematodes such as in the muscle mitochondria of Ascaris Iumbricoides (Cheah, 1976) and Turbatrix aceti (Atkinson, 1980).

The purpose of this study was to study the quantitative nutritional requirement of cytochrome $c$ by $c$. elegans in a completely chemically defined medium at various surface area exposures. Since ATP is produced via the electron transport chain, the effect of dietary cytochrome $c$ as well as surface area exposures of the culture medium on ATP production were investigated in this nematode. 
MATERIALS AND METHODS

\section{Stock Medium}

Stock culture of $c$. elegans was maintained in the medium containing $4 \%$ Hy-SOY (Sigma, St. Louis, MO), $1 \%$ yeast extract (Sigma, St. Louis, MO), and $10 \%$ heated liver extract (Sayre et al., 1963).

\section{Experimental Media}

Both a control and experimental media were prepared. The "control medium" consisted of $c$. briggsae Maintenance Medium (CbMM, 1x) (Buecher et al., 1966), which was supplemented with cytochrome c $(50 \mu \mathrm{g} / \mathrm{ml}), \beta$-sitosterol (50 $\mu \mathrm{g} / \mathrm{ml})$, and potassium acetate ( $5 \mathrm{mg} / \mathrm{ml}$ ) (Lu et al., 1978). Other experimental media were also prepared by varying the cytochrome c concentrations $(0,13,25,100$, and $200 \mu \mathrm{g} / \mathrm{ml}$ ). Cytochrome $\mathrm{c}$ at $50 \mu \mathrm{g} / \mathrm{ml}$ was used as the control since this is the level routinely used in the previous studies (Lu et al., 1978; Lu et al., 1983; Sun et al., 1986).

\section{Cultivation Conditions}

c. elegans from stock medium were washed according to the procedure of $\mathrm{Lu}$ and co-workers (1978). One-tenth $\mathrm{ml}$ samples of washed $c$. elegans containing approximately 3,000 nematodes were inoculated into $5 \mathrm{ml}$ of test medium in $18 \mathrm{x}$ $150 \mathrm{~mm}$ tubes to give an initial population of approximately 600 nematodes/ml. Duplicates were prepared for each test medium. The samples were tilted at $10^{\circ}, 15^{\circ}$, and $20^{\circ}$ angles 
on a tissue culture rotator $\left(1 \mathrm{rpm}, 20^{\circ} \mathrm{C}\right)$. The $15^{\circ}$ angle was used in the previous nematode studies (Lu et al., 1978; Lu et al., 1983; Sun et al., 1986). Varying the angles at $10^{\circ}, 15^{\circ}$ and $20^{\circ}$ resulted in three different surface area exposures of the culture medium, which were estimated to be $12 \mathrm{~cm}^{2}$ (large), $8.2 \mathrm{~cm}^{2}$ (medium or control), and $4.3 \mathrm{~cm}^{2}$ (small), respectively. The population growth was measured by counting dilutions of the culture under a dissecting microscope on days 7, 14, and 21 (day 23 for the medium surface area).

Extraction and Measurement of ATP

Extraction and measurement of ATP were performed on days 7, 14 and 21 (day 23 for the medium surface area) according to the methods developed by Turner Designs (1985). One part nematode culture $(0.1 \mathrm{ml})$ was treated with nine parts $90 \%$ dimethyl sulfoxide (DMSO) $(0.9 \mathrm{ml})$ (Sigma, st. Louis, MO) in a screw cap test tube (13 x $100 \mathrm{~mm})$. This mixture ( $1 \mathrm{mI}$ ) was vortexed for $5 \mathrm{sec}$ and allowed to remain at room temperature for $2 \mathrm{~min}$, after which it was diluted with $5 \mathrm{ml}$ of hepes buffer (pH 7.75). Thus, the original $0.1 \mathrm{ml}$ nematode culture was diluted 60-fold in the final volume of a $6 \mathrm{ml}$ mixture $(D F=60)$. The mixture was vortexed for 1-2 sec and this culture extract was used for ATP assay. Culture extracts $(100 \mu l)$ were pipetted into six polypropylene cuvettes $(8 \times 50 \mathrm{~mm})$. A hundred microliter of ATP internal standard $\left(5 \times 10^{-5} \mu \mathrm{g} / \mu \mathrm{l}\right)$ was added into three 
cuvettes. The volume of the remaining cuvettes was adjusted with $100 \mu l$ hepes buffer. A final volume of $300 \mu l$ was obtained after the addition of $100 \mu l$ of the luciferinluciferase to all six cuvettes. The light emitted from the enzymatic reaction was measured by a luminometer (Turner Designs, Model 20) at $560 \mathrm{~nm}$ in the absence of fluorescent light.

The amount of ATP was calculated using the formula reported by Turner Designs (1983).

$$
\operatorname{ATP}(\mu \mathrm{g} / \text { nema })=\left(\frac{\mathrm{LUs}}{\mathrm{LU}(\mathrm{s}+\mathrm{is})-\mathrm{LUS}} \times \operatorname{ATPis} \times \mathrm{DF}\right) \div \mathrm{N}
$$

where:

$$
\begin{aligned}
& \text { LUs = Light output of sample } \\
& \text { LU(s + is) = Light output of (sample + internal standard) } \\
& \text { ATPis = ATP internal standard }\left(5 \times 10^{-3} \mu \mathrm{g} /\right. \text { cuvette) } \\
& \text { DF = Dilution factor = } 60 \\
& \text { N = Number of nematodes in } 0.1 \mathrm{ml} \text { sample } \\
& \text { Since the luciferin-luciferase reaction with ATP is } \\
& \text { dependent on pH, ionic strength, and the kinds of ions } \\
& \text { present in the medium, internal standardization was used in } \\
& \text { the measurement of ATP to correct for the effects of these } \\
& \text { variables on the enzymatic reaction. }
\end{aligned}
$$


RESULTS

Quantitative Requirement of Cytochrome $c$ and surface Area Exposures on Population Growth

The population growth curves of $c$. elegans as affected by the various concentrations of cytochrome c $(0,13,25$, 50, 100 , and $200 \mu \mathrm{g} / \mathrm{ml}$ ) at three different surface areas (large, medium, and small) are shown in Fig. 1-3.

c. elegans showed a logarithmic growth pattern during the first 14 days after which the growth slowed down by the end of the third week (day 21). When c.. elegans was grown in the medium containing no cytochrome $c$, the final population growth was consistently the lowest at all three surface areas. In addition, many small-sized adults and dead nematodes were observed. In general, the population increased as the concentration of cytochrome $c$ increased. At all three surface areas, $200 \mu \mathrm{g} / \mathrm{ml}$ cytochrome c supported the highest population growth.

The effects of cytochrome $c$ and surface area at different levels on the final population growth (on day 21) of c. elegans are shown in Fig. 4. In general, the population was the lowest at zero level cytochrome $c$ with the small surface area exposure. The population growth increased as levels of cytochrome $c$ and surface area were increased. At $13 \mu \mathrm{g} / \mathrm{ml}$ of cytochrome $\mathrm{c}$, the population growth increased slightly as the surface area exposure was increased. As the levels of cytochrome $c$ were increased to 
25 and $50 \mu \mathrm{g} / \mathrm{ml}$, the population growth at the large and medium surface area exposures increased more rapidly than that of the small surface area. As the levels of cytochrome c were further increased from 50 to $200 \mu \mathrm{g} / \mathrm{ml}$, only the population growth of nematodes at the large surface area showed a consistent linear increase. As shown in Fig.4, population growth increased linearly as cytochrome $c$ increased from 13 to $200 \mu \mathrm{g} / \mathrm{ml}$ at only the large surface area. At $200 \mu \mathrm{g} / \mathrm{ml}$ cytochrome c, the population growth (nematodes/ml) was 93,000 at the large surface area, 65,000 at the medium surface area, and 32,000 at the small surface area.

Effects of Surface Area Exposures on ATP Content of Nematode Results of this study are summarized in Table $I$. The ATP content of $c$. elegans did not change in direct proportion to the cytochrome c concentration. For example, on day 7 at the large surface area, the ATP $\left(\mu g \times 10^{-5}\right)$ per nematode was 11 at $200 \mu \mathrm{g} / \mathrm{ml}$ cytochrome $\mathrm{c}$ and 17 at $13 \mu \mathrm{g} / \mathrm{ml}$ cytochrome $c$. On day 21 at the large surface area, ATP per nematode was 4 at $200 \mu \mathrm{g} / \mathrm{ml}$ cytochrome $\mathrm{c}$ and 11 at $50 \mu \mathrm{g} / \mathrm{ml}$ cytochrome c. Since cytochrome c concentrations had no consistent effect on the ATP content of $c$. elegans, the mean ATP for each surface area was used for comparison. The consistent increase of the mean ATP at large and medium surface areas was obvious especially during log phase (days 7 and 14). On day 7 , the mean ATP $\left(\mu \mathrm{g} \times 10^{-5} /\right.$ nema) was 13 
at large surface area, 7.3 at medium surface area, and 5.7 at small surface area. On day 14, the mean ATP was 11 at large surface area, 9.3 at medium surface area, and 4.3 at small surface area.

\section{DISCUSSION}

In this study, the quantitative requirement of cytochrome $c(0-200 \mu \mathrm{g} / \mathrm{ml})$ for the population growth of C. elegans was demonstrated. Cytochrome c at $200 \mu \mathrm{g} / \mathrm{ml}$ supported the highest population growths at each of the three surface areas tested. c. elegans has a nutritional requirement of cytochrome $c$ due to its heme moiety structure. Population growth of c. elegans fails when cytochrome $c$ (or other heme sources) was not supplemented in the CbMM. Therefore, heme is an essential nutrient for c. elegans. It was further suggested (Hieb, 1977) that the requirement of a heme source could be attributed to metabolic deficiencies in the nematode: (a) an inability to synthesize the porphyrin ring structure, (b) a defect in the mechanism by which iron is introduced into the porphyrin ring, or (c) a problem in the transport of iron through the intestinal cells. In fact, a heme deficiency was demonstrated with the $\underline{c}$. briggsae Maintenance Medium (Buecher et al., 1966) which already contains a large amount of non-heme iron $(9.7 \mu \mathrm{g} / \mathrm{ml} \mathrm{Fe})$ in our study; indicating that one or combination of the above metabolic deficiencies may indeed exist in this nematode. 
The population growth was further increased by larger surface area exposure since it allowed more air to be circulated into the culture medium. As shown in Fig. 4, at $200 \mu \mathrm{g} / \mathrm{ml}$ cytochrome $c$, the population growth at the medium surface area $(65,000$ nematodes $/ \mathrm{ml})$ equalled $70 \%$ that observed for the large surface area $(93,000$ nematodes $/ \mathrm{ml})$, whereas the population growth at the small surface area $(32,000$ nematodes $/ \mathrm{ml})$ equalled only $34 \%$ that observed for the large surface area. During the logarithmic growth period (Fig. 1-3, days 7 and 14), the largest surface area was most effective in supporting population growth of C. elegans when the medium was supplemented with the highest concentration $(200 \mu \mathrm{g} / \mathrm{ml})$ of cytochrome c. c. elegans are aerobic organisms which require an adequate supply of oxygen for motility, growth, development, and reproduction (Bolla, 1980). Therefore, rapid growth in liquid medium requires vigorous and continuous aeration. The larger the slanting surface area exposed to the air, the more the oxygen was presumably aerated into the medium during rotation to support the higher population growth. In this study, the large surface area of the culture medium supported the highest population growth $(93,000$ nematodes $/ \mathrm{ml})$ at $200 \mu \mathrm{g} / \mathrm{ml}$ cytochrome c. At small surface area, many dead nematodes were found at all concentrations of cytochrome $c$, presumably as a result of oxygen deprivation.

The ATP content of $c$. elegans did not increase in 
direct proportion to the cytochrome concentration. However, ATP content of $c$. elegans grown in a medium containing no cytochrome $c$ was generally the lowest (Table I) indicating that a dietary heme source is essential for ATP production.

The effect of surface area exposure of the growth medium on ATP production by $\underline{c}$. elegans was demonstrated (Table I). The mean ATP content increased consistently at large and medium surface areas especially on days 7 and 14 . It has been documented that availability of oxygen might also account for the type of metabolic pathways used by the nematodes and affect the amount of ATP produced. The amount of ATP produced by aerobic metabolism is higher than by anaerobiosis (Atkinson, 1980). For instance, aerobic metabolism yields 38 ATP moles per glucose mole catabolized in nematodes, whereas the most efficient anaerobic pathway presently suggested for nematodes provides 5 ATP moles per mole of glucose (Barrett, 1976). Under adequate oxygen supply, the free-living $c$. elegans may use aerobic metabolic pathways (TCA cycle) coupled to the cytochrome-mediated electron transport for higher ATP production; however, when environmental oxygen supply becomes restricted, these nematodes may switch to anaerobic pathways (glycolysis pathway only), which result in lower energy production. In this study, it is postulated that there was a shortage of oxygen in the culture medium due to the competition for 
oxygen by a crowded population (e.g., 93,000 nema/ml) during the late log phase (day 21). Under such adverse condition, the nematodes may have switched to anaerobic metabolism which resulted in lower energy production. Therefore, the ATP content was consistently lower for all three surface areas, respectively, on day 21. In addition, it was suggested by the slow motility of nematodes observed on day 21.

A fluctuation of ATP content in $\underline{c}$. elegans over the growth cycle (days $7,14,21$ ) was observed. In this study, a mixture of developmental stages of $c$. elegans, which included juvenile stages, an adult reproductive period, a post reproductive period, and finally death, was present in the cultures at various phases of population growth. Nematode populations usually have a similar age structure consisting mostly of small and youth adults during the log phase (day 7, 14), but, thereafter, the proportion of larger and aged nematodes increases. According to Prosser (1973), the fluctuation of metabolic and respiration rates during the life cycle of nematodes affect ATP production. This author suggested that $\underline{c}$. elegans has a metabolic peak in the second juvenile stage and a respiration peak in the young adult stage (log phase) and that there is a gradual decline in metabolic and respiration rates as the nematodes becomes older (late log phase). This is ascribed to a general failure of metabolism in old age, which might also account 
for the decline of ATP content of nematode during the late log phase (day 21) in this study. The dramatic decline of respiration and metabolic activities in aging nematodes was also reported by Decuyper and Vanfletern (1982). A synchronized culture would eliminate the problem with a mixed-size population of various developmental stages.

We thank Dr. Robert Phillips of Turner Designs for loaning the luminometer and providing the chemical reagents. 


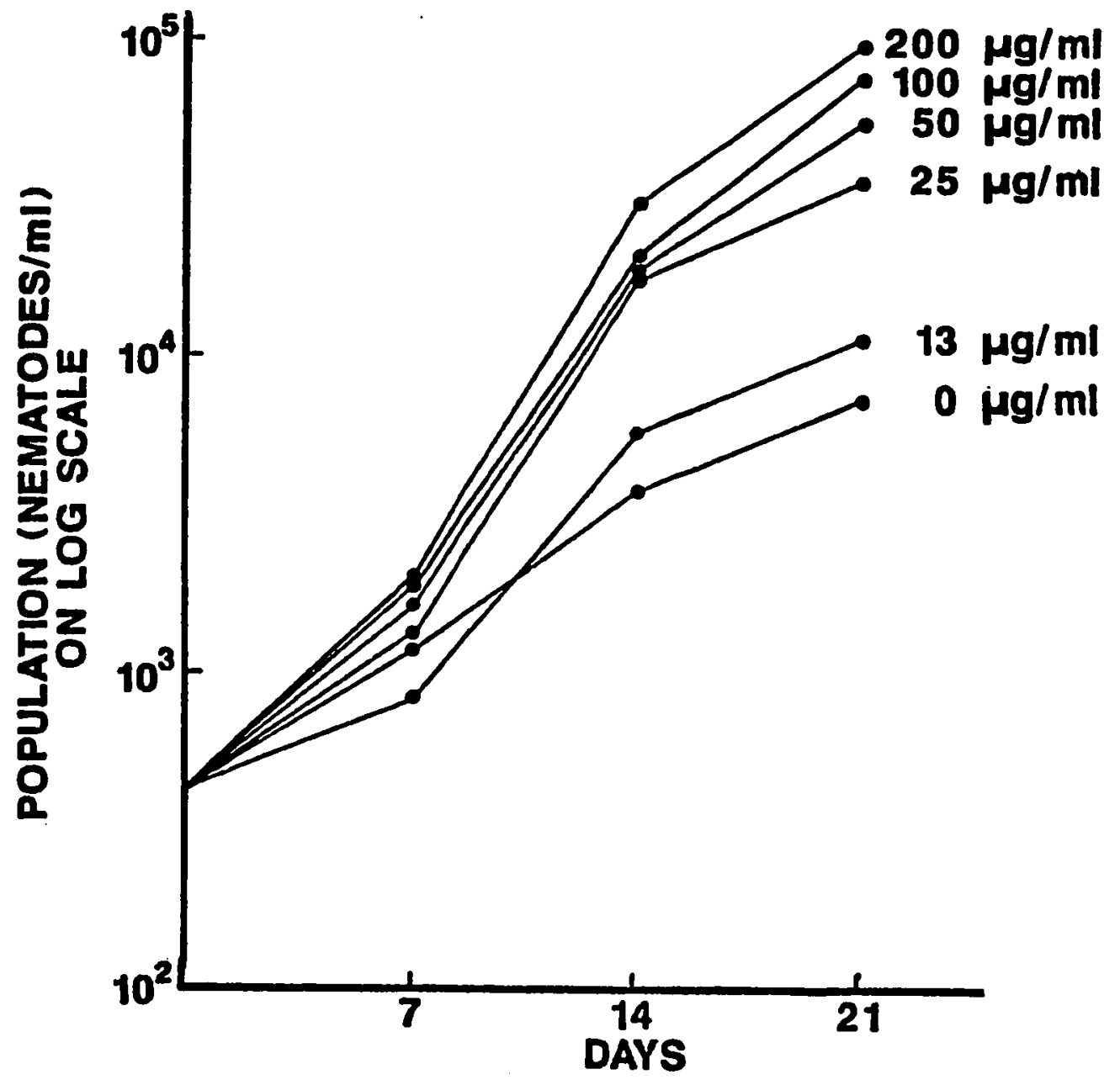

Fig. 1. Population growth of $c$. elegans at various concentrations of cytochrome $c$ and large surface area (12 $\mathrm{cm}^{2} / 5 \mathrm{ml}$ medium). The basal medium consisted of $\operatorname{CbMM}(1 \mathrm{x}), 50 \mu \mathrm{g} / \mathrm{ml} \beta$-sitosterol, and $5 \mathrm{mg} / \mathrm{ml}$ potassium acetate. Initial population: 600 nematodes/ml 


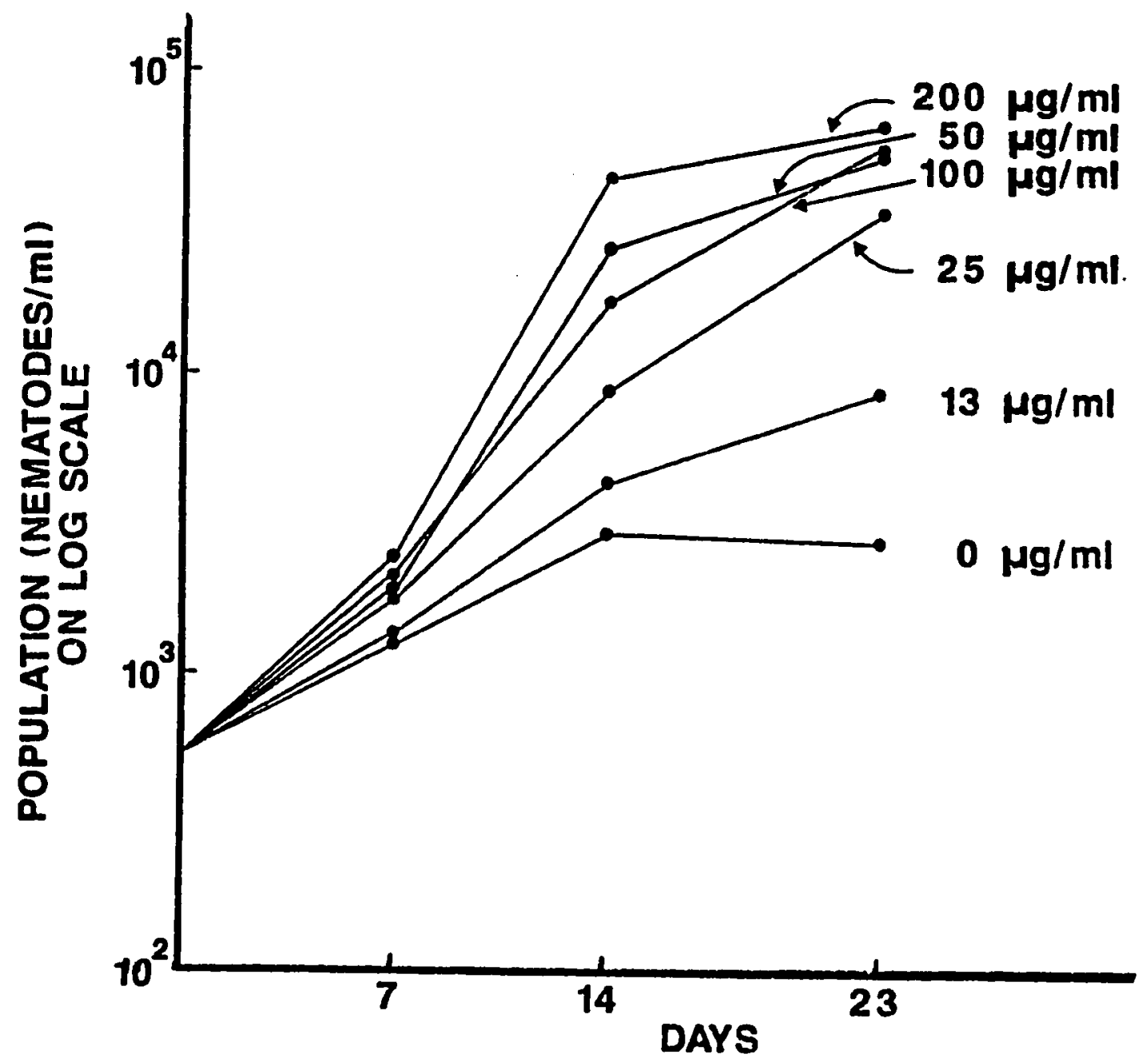

Fig. 2. Population growth of $c$. elegans at various concentrations of cytochrome $c$ and medium surface area (8.2 $\mathrm{cm}^{2} / 5 \mathrm{ml}$ medium). The basal medium consisted of $\mathrm{CbMM}(1 \mathrm{x}), 50 \mu \mathrm{g} / \mathrm{ml} \beta$-sitosterol, and $5 \mathrm{mg} / \mathrm{ml}$ potassium acetate. Initial population: 600 nematodes $/ \mathrm{ml}$ 


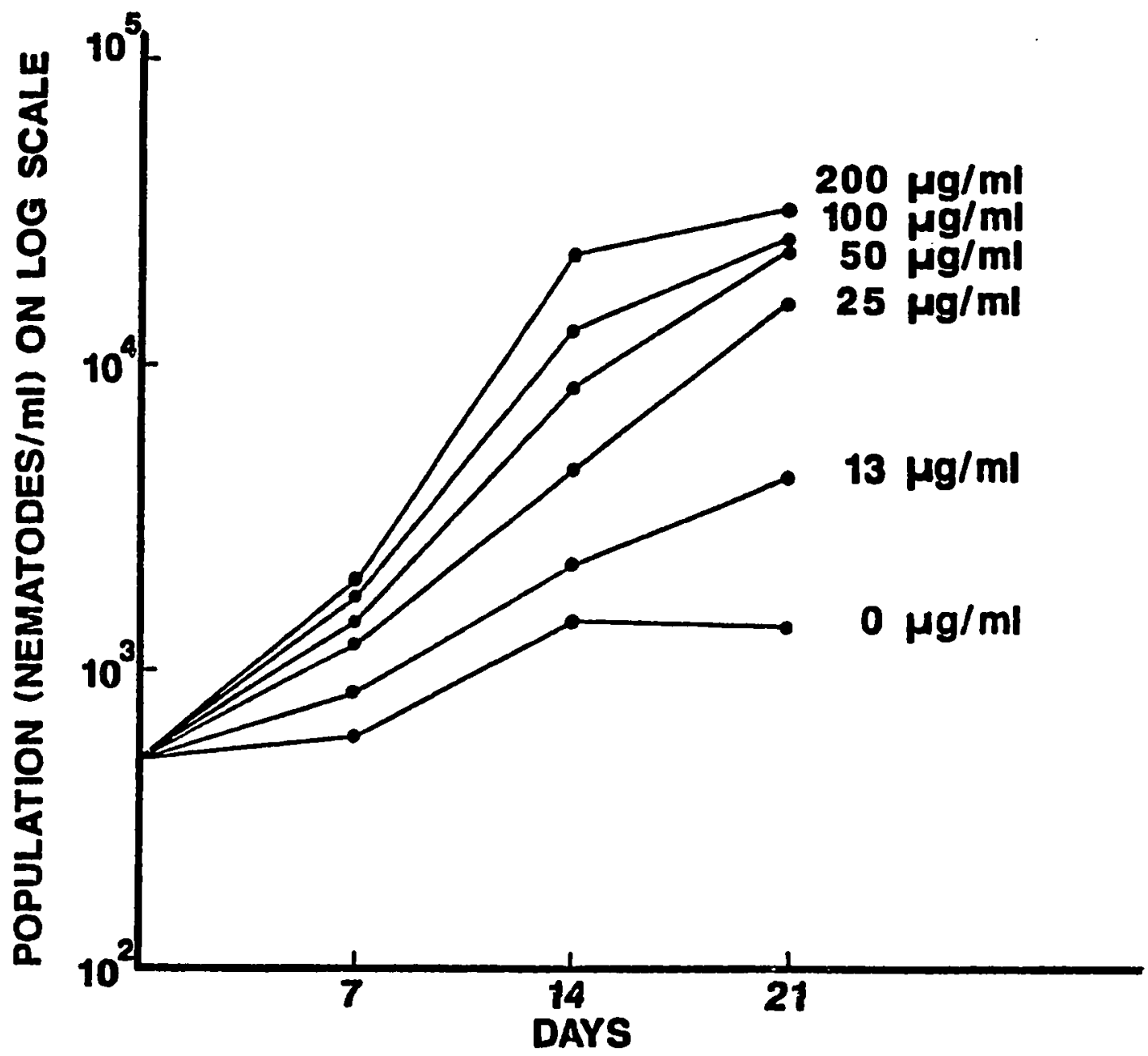

Fig. 3. Population growth of c. elegans at various concentrations of cytochrome $c$ and small surface area (4.3 $\mathrm{cm}^{2} / 5 \mathrm{ml}$ medium). The basal medium consisted of $\operatorname{CbMM}(1 \mathrm{x}), 50 \mu \mathrm{g} / \mathrm{ml} \beta$-sitosterol, and $5 \mathrm{mg} / \mathrm{ml}$ potassium acetate. Initial population: 600 nematodes/ml 


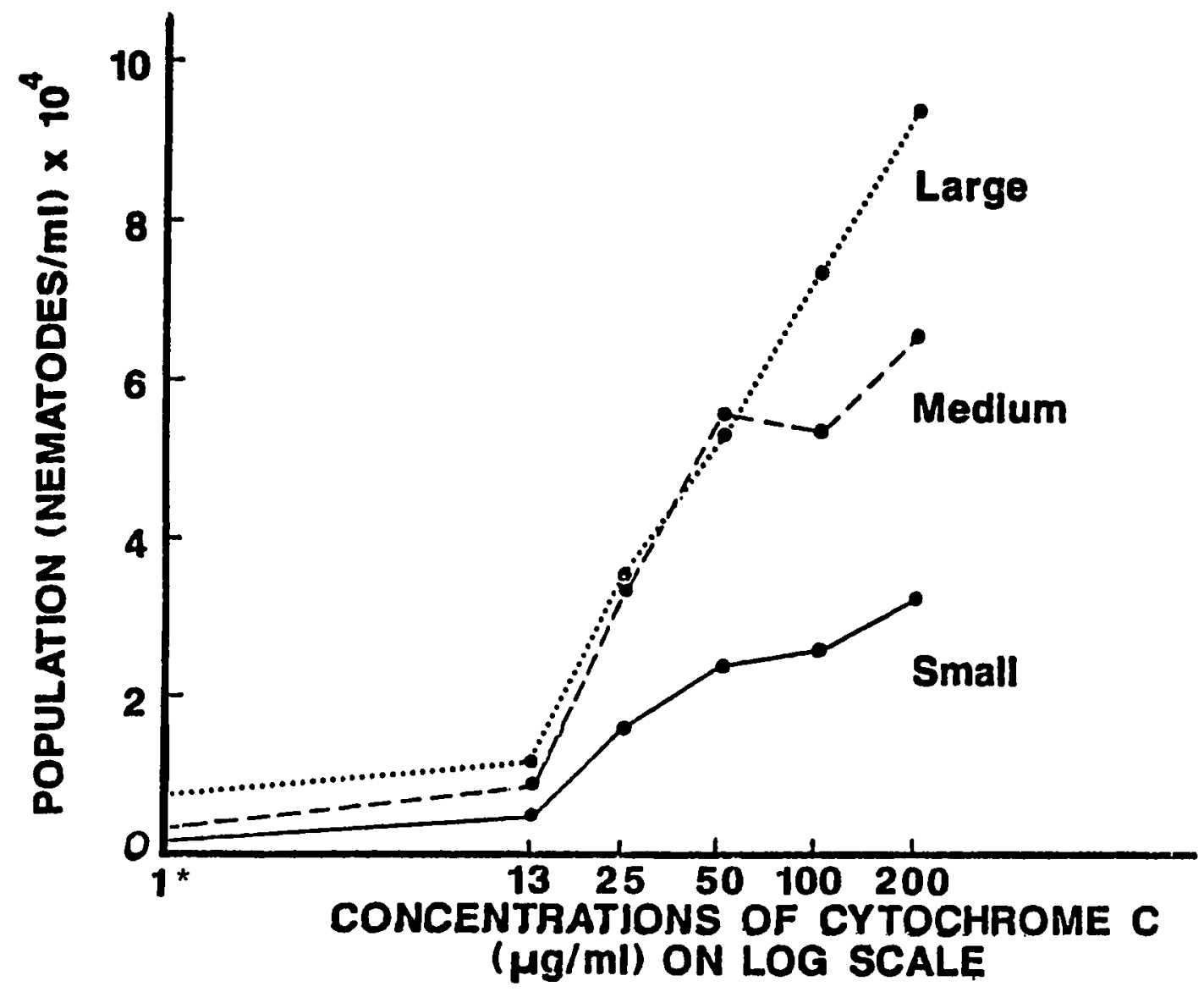

Fig. 4. Comparison of population growth at various concentrations of cytochrome $c$ and surface areas in C. elegans on day 21. The basal medium consisted of CbMM (1x), $50 \mu \mathrm{g} / \mathrm{ml} \beta$-sitosterol, and $5 \mathrm{mg} / \mathrm{ml}$ potassium acetate. Initial population: 600 nematodes/ml. * Zero concentration of cytochrome c on log scale. 
Table I

ATP production at various concentrations of cytochrome $c$ and surface areas in $c$. elegans

\begin{tabular}{ccccccccccc}
\hline $\begin{array}{c}\text { Cytochrome } \\
(\mathrm{g} / \mathrm{ml})\end{array}$ & \multicolumn{10}{c}{ ATP $\left(\times 10^{-5} \mathrm{~g}\right)$ per nematode } \\
\cline { 2 - 12 } & \multicolumn{1}{c}{ Day 7} & \multicolumn{1}{c}{ Day 14} & \multicolumn{3}{c}{ Day 21 } \\
\cline { 2 - 12 } & $\mathrm{L}^{\mathrm{a}}$ & $\mathrm{M}^{\mathrm{b}}$ & $\mathrm{S}^{\mathrm{c}}$ & $\mathrm{L}$ & $\mathrm{M}$ & $\mathrm{S}$ & $\mathrm{L}$ & $\mathrm{M}$ & $\mathrm{S}$ \\
\hline 200 & 11 & 7.3 & 6.7 & 16 & 9.7 & 7.3 & 4.0 & 3.3 & 4.3 \\
100 & 14 & 8.3 & 6.0 & 15 & 11 & 6.7 & 6.0 & 6.7 & 5.3 \\
50 & 14 & 7.0 & 6.7 & 11 & 12 & 4.3 & 11 & 6.7 & 4.0 \\
25 & 13 & 6.3 & 5.7 & 5.3 & 10 & 3.1 & 7.0 & 8.0 & 2.7 \\
13 & 17 & 7.7 & 5.0 & 7.7 & 7.3 & 2.3 & 6.0 & 6.7 & 2.0 \\
0 & 8.3 & 7.3 & 4.7 & 8.3 & 6.7 & 1.8 & 5.7 & 9.7 & 1.7 \\
\hline Mean & 13 & 7.3 & 5.7 & 11 & 9.3 & 4.3 & 6.7 & 7.0 & 3.3 \\
\hline
\end{tabular}

a Large Surface area (12 $\mathrm{cm}^{2} / 5 \mathrm{ml}$ medium)

b Medium Surface area (8.2 $\mathrm{cm}^{2} / 5 \mathrm{ml}$ medium)

c Small Surface area (4.3 $\mathrm{cm}^{2} / 5 \mathrm{ml}$ medium) 
REFERENCES

Atkinson, H.J. (1980). Respiration in nematodes. In

B.M. Zuckerman (Ed.), Nematodes as Biological Models:

Vol. 2 (pp. 101-142). Academic Press: New York.

Barrett, J. (1976) . Energy metabolism in nematodes. In $\mathrm{H}$. Vanden Bossche (Ed.), Biochemistry of parasites and the host parasite relationship (pp. 117-123). North-Holland Publisher: Amsterdam.

Bolla, R. (1980) - Nematode energy metabolism. In B.M. Zuckerman (Ed.), Nematodes as biological models Vol. 2 (pp. 166-192). Academic Press: New York.

Buecher, E.J., Hansen, E.L. \& Yarwood, E.A. (1966). Ficoll activation of a protein essential for maturation of the free-living nematode Caenorhabditis briggsae. Proceedings of Society for Experimental Biology and Medicine, 212, 390-393.

Cheah, K.S. (1976). Biochemistry of Parasites. Academic Press: New York. DeCuyper, C.D. \& Vanfleteren, J.R. (1982). Oxygen consumption during development and aging of the nematode Caenorhabditis elegans. Comparative Biochemistry and Physiology, 73A, 283-289. 
Hieb, W.F. (1977) - Qualitative requirements and utilization of nutrients: Nematode. In M. Rechcigl, Jr. (Ed.), Handbook series in nutrition and food, section D: Nutritional requirements: Vol 1 (pp. 269-288). CRC Press: Cleveland, OH. Hieb, W.F., Stokstad, E.L.R. \& Rothstein, M. (1970). Heme requirement for reproduction of a free-living nematode. Science, 168, 143-144.

Lu, N.C., Cheng, A.C. \& Briggs, G.M. (1983). A study of mineral requirements in Caenorhabditis elegans, Nematologica, 29, 425-434. Lu, N.C., Hugenberg G., Briggs, G.M. \& stokstad, E.L.R. (1978). The growth-promoting activity of several Lipidrelated compounds in the free-living Nematode Caenorhabditis briggsae. Proceedings of the society for Experimental Biology and Kedicine, 158, 187-191. Martin D.W., Mayes P.A. \& Rodwell V.W. (1983). Harper's Review of Biochemistry. Lange Medical Publication: Los Altos, CA. Nicholas, W.L. \& Jantunen, R. (1964). Caenorhabditis briggsae (Rhabditidae) under anaerobic conditions. Nematologica, 10, 409-418. 
Nicholas, W.L. \& Jantunen, R. (1966). The effect of different concentrations of oxygen and of carbon dioxide on the growth and reproduction of Caenorhabditis briggsae (Rhabditidae). Nematologica, 12, 328-336.

Prosser, C.L. (Ed.) (1973). Comparative Animal Physiology: Vol. 1. Saunders: Philadelphia. Sun, S.J., Lu, N.C., Tseng, R. \& Smith, E. (1986). Vitamin $B_{6}$ requirement and tryptophan load test in c. elegans. Federation Proceedings 45,823 . Sayre, W.F., Hansen, E.L. \& Yarwood, E.A. (1963). Biochemical aspects of the nutrition of Caenorhabditis briggsae. Experimental parasiste, 13, 98-107. Turner Designs. (1983). Luminescence Review: ATP Measurements - Theory and Practice (Bulletin 202). Turner Designs: Mountain View, CA. Turner Designs (1985). Procedure for determination of ATP, using dimethyl sulfoxide (DMSO) as extractant (ATDMSO. LTR). Turner Designs: Mountain View, CA. 
CHAPTER 3

SUMMARY AND RECOMMENDATIONS

\begin{abstract}
Summary
The effects of various cytochrome concentrations and surface area exposures of the culture medium on the population growth and ATP production of $c$. elegans were studied. Population growth increased more rapidly as cytochrome concentration increased in combination with a large surface area exposure. However, population growth increased less rapidly at small surface area exposure although cytochrome c concentration was increased to the same levels. The highest population growth $(93,000$ nematodes $/ \mathrm{ml}$ ) was found at $200 \mu \mathrm{g} / \mathrm{ml}$ cytochrome $\mathrm{c}$ and large surface area exposure $\left(12 \mathrm{~cm}^{2} / 5 \mathrm{ml}\right.$ medium). No linear relationship was found between cytochrome c concentrations and ATP content of $\underline{c}$. elegans. Rather, ATP content of c. elegans increased consistently at higher surface area exposure especially at log phase. Both cytochrome $c$ and sufficient aeration of the medium are essential to reach a higher population growth. However, under the experimental conditions in this study, the effect of aeration was more prominent than cytochrome $c$ on the ATP production by c. elegans.
\end{abstract}


Recommendations

To improve the experimental design of this study, the following suggestions are made:

1. oxygen concentrations within the culture medium could be measured and monitored constantly at each aeration angle of the tissue rotator;

2. concentrations of cytochrome $c$ higher than 200 $\mu \mathrm{g} / \mathrm{ml}$ should be tested to determine the maximum population growth of $\underline{c}$. elegans:

3. more aeration angles could be tested and repeated on rotator with vigorous aeration; and

4. since the ATP content of $c$. elegans fluctuates over the various growth cycle, synchronized rather than mixed-sized cultures could be used, and population profiles could be measured with all ATP measurements. 


\section{References}

Ahluwalia, B.K., \& Lu, N.C. (1985). Study of several growth factors for c. elegans: An animal model for studying nutrient requirements. Poster session at American Dietetic Association Annual Meeting.

Anderson, G.L., \& Dusenbery, D.B. (1977). Critical oxygen tension of Caenorhabditis elegans. Journal of Nematology, 9, 253-254.

Atkinson, H.J. (1980). Respiration in nematodes. In B.M. Zuckerman (Ed.), Nematodes as biological models: Vol. 2 (pp. 101-142). New York: Academic Press. Barrett, J. (1976). Energy metabolism in nematodes. In H. Vanden Bossche (Ed.), Biochemistry of parasites and the host parasite relationship (pp. 117-123). Amsterdam: North-Holland Publisher. Bird, A.F. (1980). The nematode cuticle and its surface. In B.M. Zuckerman (Ed.), Nematodes as biological models: Vol. 2 (pp. 213-235). New York: Academic Press.

Bolla, R. (1980) . Nematode energy metabolism. In B.M. Zuckerman (Ed.), Nematodes as biological models: Vol. 2 (pp. 166-192). New York: Academic Press. Brun, J. (1965). Genetic adaption of Caenorhabditis elegans to high temperatures. Science, 150, 10. 
Buecher, E.J., Hansen, E.I., \& Yarwood, E.A. (1966). Ficoll activation of a protein essential for maturation of the free-living nematode Caenorhabditis briggsae. Proceedings of Society for Experimental Biology and Medicine, 212, 390-393. Chapelle, E.พ., \& Levin, G.V. (1964). Rapid microbiological detection. Navy Contractor Report, 178, 8097 .

Cheah, K.S. (1976) - Biochemistry of parasites. New York: Academic Press.

Conn, R.B., Charache, P., \& Chapelle, E. (1975). Limits of applicability of the firefly luminescence ATP assay for the detection of bacteria in clinical specimens. American Journal of Clinical Pathology, 63, 493-501. Decuyper, C.D., \& Vanfleteren, J.R. (1982) . Oxygen consumption during development and aging of the nematode Caenorhabditis elegans. Comparative Biochemistry and Physiology, 73A, 283-289. Deubert, E.L., \& Zuckerman, B.M. (1968). Oxygen requirement of nematodes. Nematologica, 14, 453-455. Gershon, D. (1970). Studies on aging innematodes. I. The nematode as a model organism for aging research. Experimental Gerontology, 5, 7-12. 
Hansen, E., Buecher, E.J., \& Yarwood, E.A. (1964).

Development and maturation of caenorhabditis briggsae in response to growth factor. Nematologica, 10, 623630.

Hieb, W.F. (1977). Qualitative requirements and utilization of nutrients: Nematode. In M. Rechcigl, Jr. (Ed.), Handbook series in nutrition and food, section D: Nutritional requirements: Vol 1 (pp. 269-288). Cleveland, OH: CRC Press.

Hieb, W.F., \& Rothstein, M. (1968). Sterol requirement for reproduction of a free-living nematode. Science, 160, 778-780.

Hieb, W.F., Stokstad, E.L.R., \& Rothstein, M. (1970). Heme Requirement for reproduction of a free-living nematode. Science, 168, 143-144.

Karl, D.M. (1980). Cellular nucleotide measurements and applications in microbial ecology. Microbiological Reviews, 44, 739 .

Knust, E.A., Chappelle, E.W., \& Picciolo, G.I. (1975). A comparison of certain extracting agents for extraction of ATP from microorganisms for use in the firefly luciferase ATP assay. In E.W. Chappelle \& G.L. Picciolo (Eds.), Analytical applications of bioluminescence and chemiluminescence (pp. 90-100). Washington, DC: NASA Scientific and Technical Information office. 
Lu, N.C. (1973). Folic acid and vitamin $B_{12}$ requirements and their metabolic interrelationship in the free-living nematode Caenorhabditis briggsae. Ph.D. Dissertation, University of California, Berkeley.

Lu, N.C., Cheng, A.C., \& Briggs, G.M. (1983). A study of mineral requirements in Caenorhabditis elegans. Nematologica, 29, 425-434.

Lu, N.C., \& Goetsch, K.M. (1987) - Carbohydrate utilization in Caenorhabditis elegans - Developing an animal model for glycemic index. Symposium on recent advances in biological and medical sciences. Taipei, Taiwan.

Lu, N.C., Hieb, W.F., \& stokstad, E.I.R. (1974). Accumulation of formimino-glutamic acid in the freeliving nematode, $\underline{c}$. briggsae as related to folic acid deficiency. Proceeding of the Society of Experimental Biology and Medicine, 145, 67-69.

Lu, N.C., Hieb, W.F., \& Stokstad, E.L.R. (1976). Effect of vitamin $B_{12}$ and folate on biosynthesis of methionine from homocysteine in the nematode caenorhabditis briggsae. Proceeding of the Society of Experimental Biology and Medicine, 151, 701-704.

Iu, N.C., Hugenberg G., Briggs, G.M., \& Stokstad, E.L.R. (1978). The growth-promoting activity of several lipid-related compounds in the free-living Nematode Caenorhabditis priggsae. Proceedings of the society for Experimental Biology and Yedicine, 158, 187-191. 
Lu, N.C., Newton, C., \& Stokstad, E.L.R. (1977). The requirement of sterol and various sterol precursors in free-living nematodes. Nematologica, 23, 57-61.

Lundin, A., Rickardsson, A., \& Thore, A. (1976).

Continuous monitoring of ATP-converting reactions by purified firefly luciferase. Analytical Biochemistry, 75, 611-620.

Martin, D.W., Mayes, P.A., \& Rodwell, V.W. (1983). Harper's review of biochemistry (pp. 127-128). Los Altos, CA: Lange Medical Publications.

Marx, J.I. (1984). Caenorhabditis elegans: Getting to know you. Science, 225, 40-42. Moyer, J.D., \& Henderson, J.F. (1983). Nucleoside triphosphate specificity of firefly luciferase. Analytical Biochemistry, 131, 187-189.

Nicholas, W.I. (1984) . Biology of Free-living nematodes. London: Oxford Press. Nicholas, W.L., Hansen, E., \& Dougherty, E.c. (1962). The B-vitamins required by Caenorhabditis briggsae. Nematologica, $8,129-135$.

Nicholas, W.L., \& Jantunen, R. (1963). A biotin requirement for Caenorhabditis briggsae. Nematologica, 9, 322-338. Nicholas, W.L., \& Jantunen, R. (1964). Caenorhabditis briggsae (Rhabditidae) under anaerobic conditions. Nematologica, 10, 409-418. 
Nicholas, W.L., \& Jantunen, R. (1966). The effect of different concentrations of oxygen and of carbon dioxide on the growth and reproduction of Caenorhabditis briggsae (Rhabditidae). Nematologica, 12, 328-336.

Pertel, R. (1967). The effect of nutrients on DNA synthesis in several species of germ-free nematodes. Ph.D. Dissertation, University of California, Berkeley. Popham, J.D., \& Webster, J.M. (1979) . Cadmium toxicity in the free-living nematode, $c$. elegans. Environmental Research, 20, 183-191.

Prosser, C.I. (Ed.) (1973). Comparative animal physiology: Vol. 1 (pp. 165-211). Philadelphia:

Saunders.

Rothstein, M. (1970) . Nematode biochemistry. V: Intermediary metabolism and amino acid interconversions in Caenorhabditis briggsae. Comparative biochemistry and physiology, 14, 541-552.

Sayre, W.F., Hansen, E.I., \& Yarwood, E.A. (1963).

Biochemical aspects of the nutrition of Caenorhabditis briggsae. Experimental Parasiste, 13, 98-107. Sulston, J.E., \& Brenner, S. (1974). The DNA of Caenorhabditis elegans. Genetics, 77, 95-104. Sun, S.J., Lu, N.C., Tseng, R., \& Smith, E. (1986). Vitamin $B_{6}$ requirements and tryptophan load test in Caenorhabditis elegans. Federation Proceedings, 45: 823 . 
Turner Designs. (1983). Iuminescence review: ATP measurements - theory and practice (Bulletin 202). Mountain View, CA: Turner Designs.

Turner Designs. (1985) - Procedure for determination of ATP, using dimethyl sulfoxide (DMSO) as extractant (ATDMSO. LTR.). Mountain View, CA: Turner Designs.

Vanfleteren, J.R. (1973). Amino acid requirements of the free-living nematodes, Caenorhabditis briggsae. Nematologica, 19, 93-101.

Whitehead, T.P., Kricka, L.J., Carter, T.J.N., \& Thorpe, G.H.G. (1979), Analytical luminescence: Its potential in the clinical laboratory. clinical Chemistry, 25, $1531-1546$. 